\title{
Efficacy of decontaminants and disinfectants against Clostridium difficile
}

\author{
Prerna Vohra and lan R. Poxton
}

\begin{abstract}
Correspondence
lan R. Poxton

i.r.poxton@ed.ac.uk
\end{abstract}

Received 14 January 2011

Accepted 6 April 2011

\author{
Centre for Infectious Diseases, University of Edinburgh College of Medicine and Veterinary \\ Medicine, The Chancellor's Building, 49 Little France Crescent, Edinburgh EH16 4SB, UK
}

\begin{abstract}
Clostridium difficile is a common nosocomial pathogen transmitted mainly via its spores. These spores can remain viable on contaminated surfaces for several months and are resistant to most commonly used cleaning agents. Thus, effective decontamination of the environment is essential in preventing the transmission of $C$. difficile in health-care establishments. However, this emphasis on decontamination must also be extended to laboratories due to risk of exposure of staff to potentially virulent strains. Though few cases of laboratory-acquired infection have been reported, the threat of infection by $C$. difficile in the laboratory is real. Our aim was to test the efficacy of four disinfectants, Actichlor, MicroSol 3+, TriGene Advance and Virkon, and one laboratory decontaminant, Decon 90, against vegetative cells and spores of $C$. difficile. Five strains were selected for the study: the three most commonly encountered epidemic strains in Scotland, PCR ribotypes 106, 001 and 027, and control strains 630 and VPI 10463. MICs were determined by agar dilution and broth microdilution. All the agents tested inhibited the growth of vegetative cells of the selected strains at concentrations below the recommended working concentrations. Additionally, their effect on spores was determined by exposing the spores of these strains to different concentrations of the agents for different periods of time. For some of the agents, an exposure of $10 \mathrm{~min}$ was required for sporicidal activity. Further, only Actichlor was able to bring about a $3 \log _{10}$ reduction in spore numbers under clean and dirty conditions. It was also the only agent that decontaminated different hard, non-porous surfaces artificially contaminated with C. difficile spores. However, this too required an exposure time of more than 2 min and up to $10 \mathrm{~min}$. In conclusion, only the chlorine-releasing agent Actichlor was found to be suitable for the elimination of $C$. difficile spores from the environment, making it the agent of choice for the decontamination of laboratory surfaces.
\end{abstract}

\section{INTRODUCTION}

Clostridium difficile is the causative agent of $C$. difficile infection (CDI) (Bartlett et al., 1978; Bartlett, 2008; George et al., 1978). Though CDI is a common nosocomial infection, it is not limited to the hospital environment; community-acquired CDI and asymptomatic carriage are also common (Freeman et al., 2010).

C. difficile is acquired via the faecal-oral route as spores (Lyerly et al., 1988). Symptomatic patients shed large amounts of both vegetative cells and spores into the environment (Wilcox et al., 2003). Though vegetative cells survive under aerobic conditions for only $15 \mathrm{~min}$ on dry surfaces, they can survive for up to $6 \mathrm{~h}$ on moist surfaces (Weber et al., 2010). The spores of C. difficile, however, can persist on hospital floors for up to 5 months (Kim et al., 1981) and are resistant to several cleaning agents, especially in the presence of organic matter (Fawley et al., 2007;

Abbreviation: CDI, Clostridium difficile infection.
Wheeldon et al., 2008). Surfaces contaminated with $C$. difficile spores can facilitate cross-colonization (Fawley \& Wilcox, 2001). It has been suggested that health-care workers (and patients) acquire C. difficile from contaminated surfaces (Gerding et al., 1995; McFarland \& Stamm, 1986) such as portable commodes, bedpans, blood pressure cuffs, walls, floors, washbasins and furniture (Fekety et al., 1981; Samore et al., 1996; Weber et al., 2010). A correlation between transmission of $C$. difficile among patients and contamination of the hands of health-care workers has been clearly observed (McFarland et al., 1989).

Although C. difficile is a dreaded nosocomial pathogen, the risk of laboratory-acquired CDI has not been given much attention, in spite of the exposure of laboratory workers to relatively high inocula of $C$. difficile. However, cases of CDI have been reported in laboratory personnel (Bouza et al., 2008) as well as in health-care workers (Arfons et al., 2005; Hell et al., 2009; Ray \& Donskey, 2003). Thus, it is important to ensure proper decontamination of surfaces in the laboratory as well as proper hand-washing technique to 
Table 1. Agents used in this study

\begin{tabular}{|llll|}
\hline Agent & \multicolumn{1}{c|}{ Active ingredient(s) } & Manufacturer & $\begin{array}{c}\text { Recommended working } \\
\text { concentration }\end{array}$ \\
\hline Actichlor & Sodium dichloroisocyanurate & Ecolab & 1000 p.p.m. chlorine \\
Decon 90 & Anionic and non-anionic surfactants & Decon Laboratories & $1: 10$ dilution \\
Microsol 3+ & Tertiary alylamine and quaternary ammonium & Anachem & $1: 10$ dilution \\
& compounds & Medichem International & $1: 100$ dilution \\
TriGene Advance & Polymeric biguanide hydrochloride and organic & Antec International & $1: 100$ dilution \\
Virkon & quaternary compounds & Potassium peroxymonosulfate & \\
\hline
\end{tabular}

prevent potential transmission of $C$. difficile from the laboratory environment into the community and hospitals. The aim of this study was to test the efficacy of five commonly used agents against both vegetative cells and spores of $C$. difficile using laboratory tests as well as a more real-life surface cleaning approach.

\section{METHODS}

Bacterial strains. Five strains of $C$. difficile were used in this study: strain 630 (ribotype 012, obtained from P. Mullany, London, UK), strain VPI 10463 (obtained from Unipath, Bedford, UK), ribotype 027 (obtained from E. J. Kuijper, Leiden, The Netherlands), ribotype 001 and ribotype 106 (local strains from Edinburgh, UK). The strains were purified and maintained as spore suspensions in Robertson's cooked meat medium (Oxoid). All culturing of strains was performed anaerobically $\left(80 \% \mathrm{H}_{2}, 10 \% \mathrm{~N}_{2}, 10 \% \mathrm{CO}_{2}\right)$ at $37^{\circ} \mathrm{C}$ in a Mark III workstation (Don Whitley Scientific).

Agents. Five agents were tested in this study: Actichlor, a disinfectant routinely used in hospitals; Decon 90, a laboratory decontaminant; and three commonly used laboratory disinfectants, Microsol 3+, TriGene Advance and Virkon. The active ingredients, recommended concentrations and manufacturers are listed in Table 1.

MIC testing. MICs of the agents for the vegetative cells of the different $C$. difficile strains were determined by the Wadsworth agar dilution method (NCCLS, 2004). Strains were cultured anaerobically on blood agar at $37{ }^{\circ} \mathrm{C}$ for $24 \mathrm{~h}$, followed by culturing in pre-reduced thioglycollate broth supplemented with $5 \mu \mathrm{g}$ haemin $\mathrm{ml}^{-1}$ and $1 \mu \mathrm{g}$ vitamin $\mathrm{K}_{1} \mathrm{ml}^{-1}$ for $8 \mathrm{~h}$. This ensured that the cultures were in the exponential phase when used for MIC testing, and thus consisted of mainly vegetative cells and very few spores. These cultures were diluted to a 0.5 McFarland standard for inoculation onto pre-reduced
Brucella agar (Oxoid) supplemented with $5 \%$ defibrinated horse blood, $5 \mu \mathrm{g}$ haemin $\mathrm{ml}^{-1}$ and $1 \mu \mathrm{g}$ vitamin $\mathrm{K}_{1} \mathrm{ml}^{-1}$ containing doubling dilutions of one of the five agents ranging from the manufacturer's recommended working concentration to $1 / 1024$ of the same. The plates were incubated anaerobically at $37{ }^{\circ} \mathrm{C}$ for $48 \mathrm{~h}$ and then examined for growth. The lowest concentration of the tested agent to inhibit visible bacterial growth was recorded as the MIC of that agent. The experiments were performed in triplicate.

MICs were also performed by broth microdilution in a 96-well plate. Doubling dilutions of the five agents ranging from the manufacturer's recommended working concentration to $1 / 1024$ of the same were prepared in pre-reduced anaerobic incubation medium and $100 \mu \mathrm{l}$ of each dilution was added to wells of the plate in duplicate. To the wells, $10 \mu \mathrm{l}$ culture adjusted to a $0.5 \mathrm{McF}$ arland standard was added. The plates were incubated anaerobically at $37{ }^{\circ} \mathrm{C}$ for $48 \mathrm{~h}$ and then examined for growth by eye and by measurement of $\mathrm{OD}_{600}$. Negative controls with no added culture and positive controls without the agents were also maintained in duplicate. The lowest concentration of the tested agent to inhibit visible bacterial growth and $\mathrm{OD}_{600} \geqslant 0.1$ was recorded as the MIC of that agent. The experiments were performed in triplicate.

Preparation of spores. Strains were cultured in $500 \mathrm{ml}$ pre-reduced anaerobic incubation medium (Brown et al., 1996) anaerobically at $37{ }^{\circ} \mathrm{C}$ for 7 days. The cultures were then collected by centrifugation at $4000 \mathrm{~g}$ for $10 \mathrm{~min}$. The pellets obtained were washed twice with sterile PBS and then treated with $50 \%$ ethanol for $1 \mathrm{~h}$ with constant shaking. The pellets were collected by centrifugation, washed twice in PBS and then resuspended in $1 \mathrm{ml}$ sterile distilled water and stored at $4{ }^{\circ} \mathrm{C}$. Before each experiment, spore counts were determined from 10fold serial dilutions of the final spore suspension plated on blood agar and incubated for $48 \mathrm{~h}$.

Sporicidal assays. Spore preparations were standardized to $10^{6}$ spores $\mathrm{ml}^{-1}$. The agents were tested for their sporicidal activity in a

Table 2. MIC of each agent for vegetative cells of five C. difficile strains represented as a fraction of the recommended working concentration

Values are the median from both the agar-dilution and the broth microdilution methods for MIC testing.

\begin{tabular}{|lccccc|}
\hline Agent & Strain $\mathbf{6 3 0}$ & Strain VPI 10463 & Ribotype 027 & Ribotype 001 & Ribotype 106 \\
\hline Actichlor & $1 / 8$ & $1 / 8$ & $1 / 2$ & $1 / 8$ & $1 / 2$ \\
Decon 90 & $1 / 4$ & $1 / 4$ & $1 / 2$ & $1 / 128$ & $1 / 4$ \\
Microsol 3+ & $1 / 128$ & $1 / 128$ & $1 / 128$ & $1 / 32$ & $1 / 128$ \\
TriGene Advance & $1 / 32$ & $1 / 32$ & $1 / 4$ & $1 / 4$ & $1 / 32$ \\
Virkon & $1 / 8$ & $1 / 8$ & & & $1 / 8$ \\
\hline
\end{tabular}


Table 3. Minimum sporicidal concentration of the agents for five C. difficile strains represented as a fraction of the recommended working concentration after different times of exposure

The tests were performed in $1 \mathrm{ml}$ volumes with $10^{5}$ spores being exposed to the disinfectants.

\begin{tabular}{|c|c|c|c|c|c|c|}
\hline \multirow[t]{2}{*}{ Agent $^{*}$} & \multirow{2}{*}{$\begin{array}{c}\text { Time of exposure } \\
(\mathrm{min})\end{array}$} & \multicolumn{5}{|c|}{ Minimum sporicidal concentration } \\
\hline & & Strain 630 & Strain VPI 10463 & Ribotype 027 & Ribotype 001 & Ribotype 106 \\
\hline \multirow[t]{3}{*}{ Actichlor } & 2 & $<1 / 5$ & $<1 / 5$ & $1 / 2$ & $<1 / 5$ & $1 / 2$ \\
\hline & 10 & $<1 / 5$ & $<1 / 5$ & $<1 / 5$ & $<1 / 5$ & $<1 / 5$ \\
\hline & 30 & $<1 / 5$ & $<1 / 5$ & $<1 / 5$ & $<1 / 5$ & $<1 / 5$ \\
\hline \multirow[t]{3}{*}{ Decon 90} & 2 & 1 & $1 / 2$ & $1 / 2$ & 1 & $1 / 2$ \\
\hline & 10 & $1 / 2$ & $<1 / 5$ & $<1 / 5$ & $1 / 2$ & $<1 / 5$ \\
\hline & 30 & $<1 / 5$ & $<1 / 5$ & $<1 / 5$ & $<1 / 5$ & $<1 / 5$ \\
\hline \multirow[t]{3}{*}{ Virkon } & 2 & 1 & 1 & 1 & 1 & 1 \\
\hline & 10 & 1 & $<1 / 5$ & 1 & $<1 / 5$ & $<1 / 5$ \\
\hline & 30 & 1 & $<1 / 5$ & 1 & $<1 / 5$ & $<1 / 5$ \\
\hline
\end{tabular}

${ }^{\star}$ The minimum sporicidal concentration for Microsol 3+ and TriGene Advance for all the strains was less than 1/5 at 2, 10 and 30 min.

suspension test at the recommended working concentration and $1 / 2$ and $1 / 5$ of the same. For each test, $100 \mu \mathrm{l}$ spore suspension containing $10^{5}$ spores was added to $900 \mu \mathrm{l}$ of each of the dilutions and mixed thoroughly. At $2 \mathrm{~min}, 10 \mathrm{~min}$ and $30 \mathrm{~min}, 100 \mu \mathrm{l}$ of the test was inoculated into $900 \mu \mathrm{l}$ pre-reduced anaerobic incubation medium, mixed and incubated at $37^{\circ} \mathrm{C}$ for 5 days in duplicate. Positive controls without any disinfectant and negative controls without spores were also maintained in duplicate to check that the medium was sustaining the germination of spores and growth of the resulting vegetative cells and that it was not contaminated, respectively. The tubes were examined for growth and the lowest concentration of the agent showing no growth was recorded as the minimum sporicidal concentration. Samples from tubes with no visible growth were plated to identify cidal or static activity and these were examined for growth after 5 days of anaerobic incubation.

Determination of $\log _{10}$ reduction. To determine the $\log _{10}$ reduction in $C$. difficile spores in suspension tests, spores were treated with the cleaning agents at the recommended working concentration in the presence or absence of organic matter. For the tests in the absence of organic matter, $100 \mu \mathrm{l}$ spores in distilled water (approx. $10^{4}$ spores $\mathrm{ml}^{-1}$ ) was added to $900 \mu \mathrm{l}$ agent. After $10 \mathrm{~min}$, the spores were collected by centrifugation at $16000 \mathrm{~g}$ for $2 \mathrm{~min}$. The spore pellets were washed twice with $1 \mathrm{ml}$ distilled water. The spores were then resuspended in $1 \mathrm{ml}$ distilled water and $100 \mu$ of this suspension was spread onto blood agar plates in duplicate and incubated at $37{ }^{\circ} \mathrm{C}$ anaerobically for $48 \mathrm{~h}$. Untreated positive controls were maintained in duplicate. For the tests in the presence of organic matter, BSA (Sigma) was introduced into the test at a final concentration of $0.27 \%$. The $\log _{10}$ reduction was calculated as $\log _{10}\left(N_{0} / N_{10}\right)$, where $N_{0}=$ the number of spores in the positive control and $N_{10}=$ the number of viable spores recovered from the test at $10 \mathrm{~min}$.

Surface decontamination testing. Five different surfaces were used in this study: aluminium, glass, plastic, self-adhesive vinyl tiles and white ceramic tiles. The surfaces were autoclaved and dried in a hot air oven before use: the self-adhesive vinyl tiles could not be autoclaved and were cleaned with $70 \%$ ethanol before use. On all the clean surfaces, squares of approximately $1 \mathrm{~cm}^{2}$ were marked out with a wax crayon. These were then artificially contaminated with spores of the five $C$. difficile strains and tested for cleaning efficiency with all the cleaning agents. Each square was contaminated with $10 \mu \mathrm{l}$ spore suspension $\left(10^{5}\right.$ spores $\left.\mathrm{ml}^{-1}\right)$ and left to air dry for $2 \mathrm{~h}$. Fifty microlitres of cleaning agent at the manufacturer's recommended concentration was then added to the square on top of the dried spore suspension. After $2 \mathrm{~min}$ and $10 \mathrm{~min}$, the area was scratched with a pipette tip 10 times in an attempt to mimic scrubbing and the agent was aspirated. The area was then washed with $100 \mu \mathrm{l}$ distilled water. The aspirated agent and wash were added to $850 \mu \mathrm{l}$ distilled water to obtain a final volume of $1 \mathrm{ml}$. One hundred microlitres of this was plated on blood agar and incubated anaerobically for $48 \mathrm{~h}$. The surfaces were also cleaned only with water and these served as positive

Table 4. Mean $\log _{10}$ reduction in C. difficile spores of five strains in the absence and presence of organic matter

The $\log _{10}$ reduction is a mean of the values obtained for all five C. difficile strains.

\begin{tabular}{|lcc|}
\hline \multirow{2}{*}{ Agent } & \multicolumn{2}{c|}{$\log _{10}$ reduction $($ mean \pm SEM) } \\
\cline { 2 - 3 } & Organic matter negative & Organic matter positive \\
\hline Actichlor & $3.093 \pm 0.2239$ & $3.076 \pm 0.2429$ \\
Decon 90 & $0.5159 \pm 0.06722$ & $0.3384 \pm 0.101$ \\
Microsol 3+ & $1.519 \pm 0.1025$ & $0.7288 \pm 0.1294$ \\
TriGene Advance & $1.698 \pm 0.0806$ & $0.5399 \pm 0.09384$ \\
Virkon & $1.171 \pm 0.1705$ & $0.1657 \pm 0.04113$ \\
\hline
\end{tabular}


controls. The $\log _{10}$ reduction was calculated as above from two independent experiments.

Statistical analysis. Statistical analyses were performed using GraphPad Prism 4.0 software. In order to compare agents and strains, one-way analysis of variance (ANOVA) was performed.

\section{RESULTS AND DISCUSSION}

\section{Efficacy against vegetative cells}

The growth of vegetative C. difficile was effectively suppressed by all the agents tested. The MICs of all agents for the strains were found to be the same by agar dilution and broth microdilution and these values were lower than the manufacturer's recommended concentration (Table 2). However, for Actichlor, Decon 90 and Virkon, higher concentrations seemed to be required to destroy vegetative cells of the epidemic ribotypes 027,001 and 106. Microsol $3+$ appeared to be the most effective agent, active at a 128fold dilution of the recommended concentration, followed by TriGene, which was effective at a 32-fold dilution of the recommended concentration. Actichlor, used for routinely cleaning hospitals, was effective at its recommended concentration, but less than a 2 -fold dilution was unable to inhibit the growth of the hypervirulent ribotype 027 . These observations suggest that the epidemic ribotypes may have a greater resistance to commonly used cleaning agents. Also, they emphasize the importance of preparing these agents at the correct concentration.

\section{Efficacy against spores}

The agents tested were also found to be sporicidal at the recommended concentration in suspension tests at 2, 10 and $30 \mathrm{~min}$ of testing (Table 3). Once again it was observed that ribotype 027 required a greater concentration of Actichlor for destruction of its spores. This was true for the epidemic ribotype 106 as well. For Virkon, any dilution below the recommended concentration was not sporicidal at $2 \mathrm{~min}$, making it a less effective disinfectant than Actichlor. Interestingly, Microsol $3+$ and TriGene Advance were found to be sporicidal at a fivefold dilution of the recommended concentration even at $2 \mathrm{~min}$ of exposure. However, a neutralizer was not used in these experiments, and the agents were not removed by washing: they were diluted 10 -fold into the recovery medium. Thus, it is possible that there was a prolonged exposure of the spores to low but effective concentrations of the agents tested.

\section{Effect of organic matter on efficacy}

All the selected agents except Decon 90 are marketed as sporicidal agents. Thus, it was of interest to determine the $\log _{10}$ reduction in spore numbers brought about by them at the recommended concentration. Under clean conditions, Actichlor was found to be the most effective
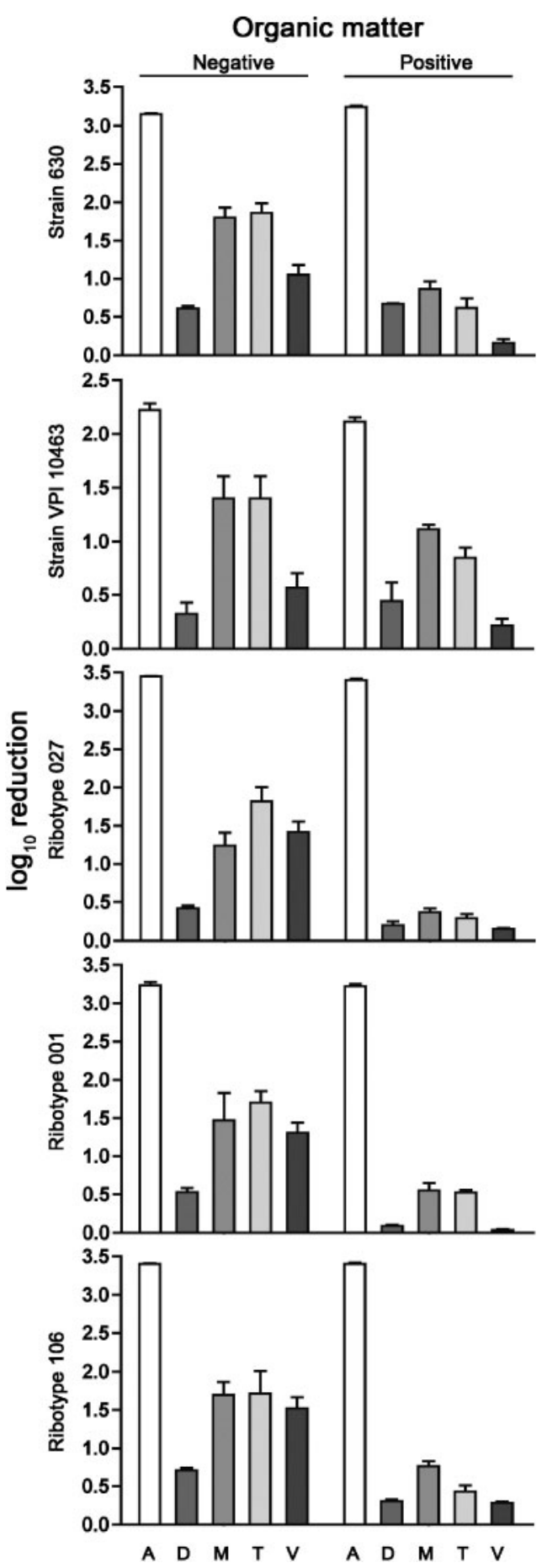

Fig. 1. Efficacy of Actichlor (A), Decon 90 (D), Microsol 3+ (M), TriGene Advance ( $\mathrm{T}$ ) and Virkon (V) ( $\log _{10}$ reduction) against the spores of five strains of $C$. difficile in the absence and presence of organic matter. Only Actichlor effectively destroyed spores of all the strains in the absence or presence of organic matter, causing 3 $\log _{10}$ reduction in spores. The efficacy of all the other agents decreased significantly in the presence of organic matter, especially in destroying spores of the epidemic ribotypes 027 , 001 and 106. Bars indicate \pm SEM of two experiments. 


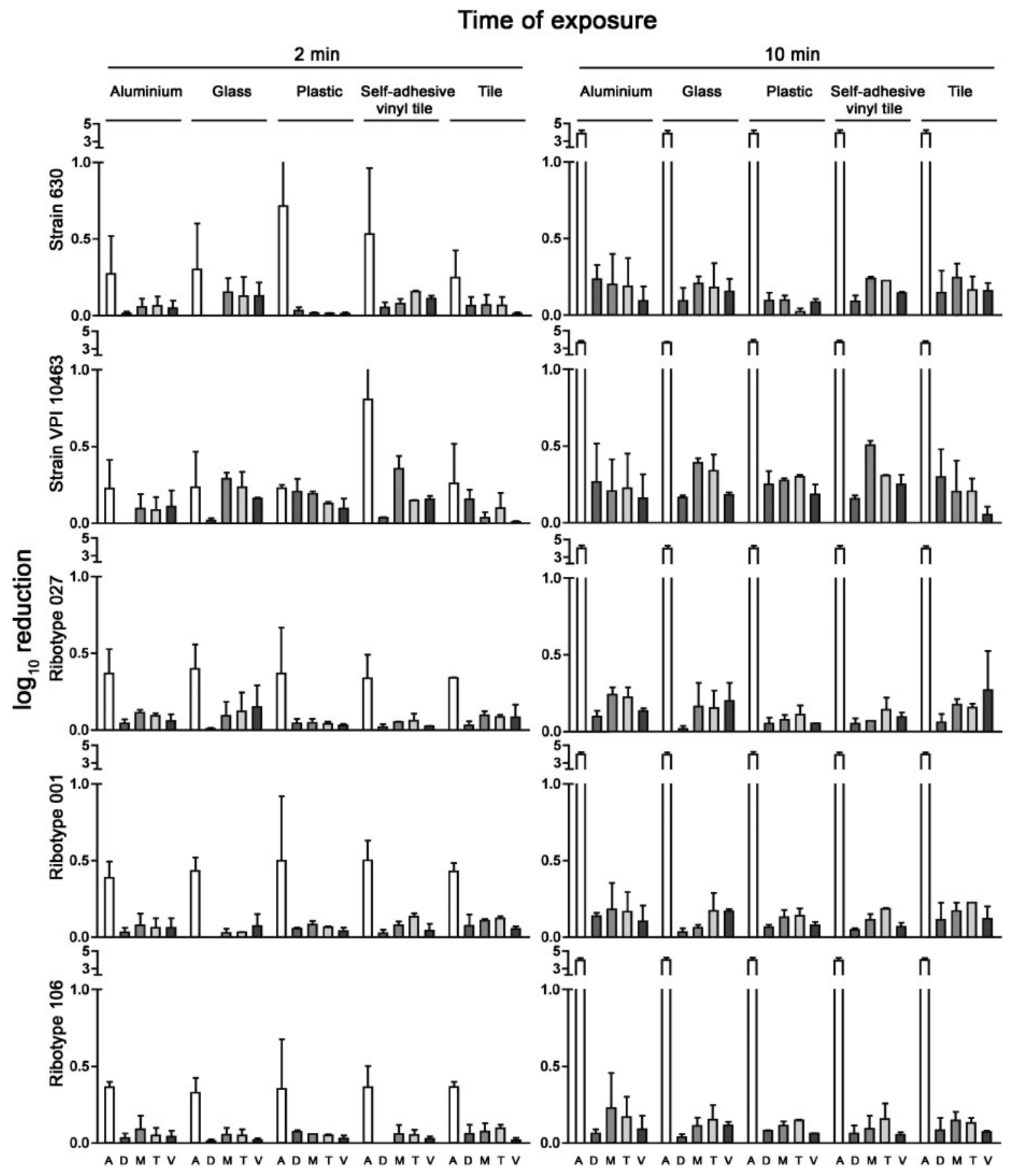

Fig. 2. Decontamination of different surfaces contaminated with spores of five C. difficile strains by Actichlor (A), Decon 90 (D), Microsol 3+ (M), TriGene Advance ( $T$ ) and Virkon (V) tested at 2 min and 10 min of exposure. Actichlor (A) was the most effective decontaminant at both the time points and destroyed $100 \%$ of spores of all the strains by 10 min. The other agents fared poorly, especially against the epidemic ribotypes 027,001 and 106. Bars indicate \pm SEM of two experiments.

sporicidal agent $(P<0.001)$, bringing about a $3 \log _{10}$ reduction of $C$. difficile spores at $10 \mathrm{~min}$, at which time Microsol 3+, TriGene Advance and Virkon only caused approximately $1.5,1.7$ and $1.2 \log _{10}$ reduction (Table 4 ). However, these disinfectants were still significantly more effective than Decon $90(P<0.001$ compared to Microsol $3+$ and TriGene Advance; $P<0.01$ compared to Virkon). The superior efficacy of chlorine-releasing agents as compared to peroxy compounds against the spores of $C$. difficile has been observed previously (Lawley et al., 2010). 
No inter-strain differences were observed, except when Decon 90 was used; the least $\log _{10}$ reduction was observed for ribotype $027(P<0.05)$. In the presence of organic matter, the efficacy of all the cleaning agents, except Actichlor, dropped considerably. Actichlor was the most effective disinfectant even in the presence of organic matter $(P<0.001)$. Of note was the drop in efficacy of Virkon from approximately $1.2 \log _{10}$ in the absence of organic matter to approximately $0.2 \log _{10}$ in the presence of it. Also, interestingly, in the presence of organic matter, for all the agents except Actichlor, the $\log _{10}$ reduction for the epidemic strains was more markedly reduced as compared to that for the non-epidemic strains (Fig. 1). Although for Actichlor, Microsol 3+ and TriGene Advance this difference was not significant, when using Virkon, ribotype 001 was the least effectively destroyed strain $(P<0.05)$, and when using Decon 90, strain 630 was the most effectively destroyed $(P<0.001)$. As contamination with organic matter is common in the environment, the efficacy of cleaning agents in its presence is of greater practical significance. From the observations above, it is clear that chlorine-based agents are a better choice for disinfection, especially to eliminate the currently epidemic $C$. difficile strains.

\section{Surface decontamination}

To test the decontamination of surfaces using the selected agents, $1 \mathrm{~cm}^{2}$ areas were artificially contaminated with $10^{3}$ spores of each strain, allowed to dry and then cleaned, in an attempt to mimic a real-life situation. Further, washing of the surface was performed by aspiration of disinfectant and subsequent washes. It was observed that only the chlorinereleasing Actichlor was able to completely decontaminate all the surfaces tested; however, it required more than $2 \mathrm{~min}$ and up to $10 \mathrm{~min}$ to see this effect (Fig. 2). For all the other agents, although there was a greater $\log _{10}$ reduction in spore numbers after $10 \mathrm{~min}$ of treatment, it was not significant. Here too it was found that the epidemic strains were less effectively cleaned. Spores of strain 630 , which was previously epidemic, were also more resistant to the cleaning, while spores of VPI 10463, which is rarely isolated from patients, were the most effectively destroyed. Thus, though chlorine-releasing agents destroy C. difficile spores, the contact times required for surfaces to be decontaminated might be unrealistic due to time constraints as well as the odour, corrosive effects on surfaces and irritation to users (Block, 2004; Ungurs et al., 2011). However, the natural environment might not be as heavily contaminated as the surfaces in these experiments and thus may be more efficiently cleaned. In the laboratory, however, contamination of surfaces by high concentrations of spores is a possibility, and they must be cleaned and decontaminated carefully and thoroughly.

The contaminated environment is important in the transmission of C. difficile (Fawley \& Wilcox, 2001; Weber et al., 2010), and just as in hospitals, laboratories can be a source of transmission of CDI, due to both the virulent types of strains and the high concentrations of $C$. difficile routinely used. Reports of laboratory-acquired CDI led us to evaluate the type of disinfectants and cleaning agents used in our laboratory in this study. From these experiments, which are preliminary and do not strictly follow the guidelines for disinfectant testing, we can conclude that vegetative cells of $C$. difficile as well as spores can be destroyed by a variety of agents in suspension tests with long contact times. However, hard non-porous surfaces were only decontaminated by the use of a chlorine-releasing agent. Even then, a contact time of up to $10 \mathrm{~min}$ was required to eliminate high concentrations of C. difficile spores. Thus, chlorine-releasing agents should be the decontaminants of choice, not only in hospitals (Fraise, 2011), but also in laboratories.

\section{ACKNOWLEDGEMENTS}

This work is part of a $\mathrm{PhD}$ funded by the Overseas Research Students Awards Scheme and the University of Edinburgh Centre for Infectious Diseases PhD Studentship. We would like to thank Alexander Phythian-Adams and Dr Surekha Reddy for providing some of the agents, and Malcolm Baldock for laboratory assistance. This work was presented as a poster at the Third International Clostridium difficile Symposium, Bled, Slovenia, September 2010.

\section{REFERENCES}

Arfons, L., Ray, A. J. \& Donskey, C. J. (2005). Clostridium difficile infection among health care workers receiving antibiotic therapy. Clin Infect Dis 40, 1384-1385.

Bartlett, J. G. (2008). Historical perspectives on studies of Clostridium difficile and C. difficile infection. Clin Infect Dis 46 (Suppl. 1), S4-S11.

Bartlett, J. G., Moon, N., Chang, T. W., Taylor, N. \& Onderdonk, A. B. (1978). Role of Clostridium difficile in antibiotic-associated pseudomembranous colitis. Gastroenterology 75, 778-782.

Block, C. (2004). The effect of Perasafe and sodium dichloroisocyanurate (NaDCC) against spores of Clostridium difficile and Bacillus atrophaeus on stainless steel and polyvinyl chloride surfaces. J Hosp Infect 57, 144-148.

Bouza, E., Martin, A., Van den Berg, R. J. \& Kuijper, E. J. (2008). Laboratory-acquired Clostridium difficile polymerase chain reaction ribotype 027: a new risk for laboratory workers? Clin Infect Dis 47, 1493-1494.

Brown, R., Collee, J. G. \& Poxton, I. R. (1996). Bacteroides, Fusobacterium and other Gram-negative anaerobic rods; anaerobic cocci; identification of anaerobes. In Mackie and McCartney Practical Medical Microbiology, pp. 501-519. Edited by J. G. Collee, A. G. Fraser, B. P. Marmion \& A. Simmons. London: Churchill Livingstone.

Fawley, W. N. \& Wilcox, M. H. (2001). Molecular epidemiology of endemic Clostridium difficile infection. Epidemiol Infect 126, 343350.

Fawley, W. N., Underwood, S., Freeman, J., Baines, S. D., Saxton, K., Stephenson, K., Owens, R. C., Jr \& Wilcox, M. H. (2007). Efficacy of hospital cleaning agents and germicides against epidemic Clostridium difficile strains. Infect Control Hosp Epidemiol 28, 920-925.

Fekety, R., Kim, K. H., Brown, D., Batts, D. H., Cudmore, M. \& Silva, J., Jr (1981). Epidemiology of antibiotic-associated colitis; 
isolation of Clostridium difficile from the hospital environment. Am J Med 70, 906-908.

Fraise, A. (2011). Currently available sporicides for use in healthcare, and their limitations. J Hosp Infect 77, 210-212.

Freeman, J., Bauer, M. P., Baines, S. D., Corver, J., Fawley, W. N., Goorhuis, B., Kuijper, E. J. \& Wilcox, M. H. (2010). The changing epidemiology of Clostridium difficile infections. Clin Microbiol Rev 23, 529-549.

George, R. H., Symonds, J. M., Dimock, F., Brown, J. D., Arabi, Y., Shinagawa, N., Keighley, M. R., Alexander-Williams, J. \& Burdon, D. W. (1978). Identification of Clostridium difficile as a cause of pseudomembranous colitis. BMJ 1, 695 .

Gerding, D. N., Johnson, S., Peterson, L. R., Mulligan, M. E. \& Silva, J., Jr (1995). Clostridium difficile-associated diarrhea and colitis. Infect Control Hosp Epidemiol 16, 459-477.

Hell, M., Indra, A., Huhulescu, S. \& Allerberger, F. (2009). Clostridium difficile infection in a health care worker. Clin Infect Dis 48, 1329.

Kim, K. H., Fekety, R., Batts, D. H., Brown, D., Cudmore, M., Silva, J., Jr \& Waters, D. (1981). Isolation of Clostridium difficile from the environment and contacts of patients with antibiotic-associated colitis. J Infect Dis 143, 42-50.

Lawley, T. D., Clare, S., Deakin, L. J., Goulding, D., Yen, J. L., Raisen, C., Brandt, C., Lovell, J., Cooke, F. \& other authors (2010). Use of purified Clostridium difficile spores to facilitate evaluation of health care disinfection regimens. Appl Environ Microbiol 76, 6895-6900.

Lyerly, D. M., Krivan, H. C. \& Wilkins, T. D. (1988). Clostridium difficile: its disease and toxins. Clin Microbiol Rev 1, 1-18.

McFarland, L. V. \& Stamm, W. E. (1986). Review of Clostridium difficile-associated diseases. Am J Infect Control 14, 99-109.
McFarland, L. V., Mulligan, M. E., Kwok, R. Y. \& Stamm, W. E. (1989). Nosocomial acquisition of Clostridium difficile infection. $N$ Engl J Med 320, 204-210.

NCCLS (2004). Methods for Antimicrobial Susceptibility Testing of Anaerobic Bacteria, Approved Standard, 6th edn. NCCLS document M11-A6. Wayne, PA: National Committee for Clinical Laboratory Standards.

Ray, A. J. \& Donskey, C. J. (2003). Clostridium difficile infection and concurrent vancomycin-resistant Enterococcus stool colonization in a health care worker: case report and review of the literature. Am J Infect Control 31, 54-56.

Samore, M. H., Venkataraman, L., DeGirolami, P. C., Arbeit, R. D. \& Karchmer, A. W. (1996). Clinical and molecular epidemiology of sporadic and clustered cases of nosocomial Clostridium difficile diarrhea. Am J Med 100, 32-40.

Ungurs, M., Wand, M., Vassey, M., O’Brien, S., Dixon, D., Walker, J. \& Sutton, J. M. (2011). The effectiveness of sodium dichloroisocyanurate treatments against Clostridium difficile spores contaminating stainless steel. Am J Infect Control 39, 199-205.

Weber, D. J., Rutala, W. A., Miller, M. B., Huslage, K. \& Sickbert-Bennett, E. (2010). Role of hospital surfaces in the transmission of emerging health care-associated pathogens: norovirus, Clostridium difficile, and Acinetobacter species. Am J Infect Control 38 (Suppl 1), S25-S33.

Wheeldon, L. J., Worthington, T., Hilton, A. C., Lambert, P. A. \& Elliott, T. S. J. (2008). Sporicidal activity of two disinfectants against Clostridium difficile spores. Br J Nurs 17, 316-320.

Wilcox, M. H., Fawley, W. N., Wigglesworth, N., Parnell, P., Verity, P. \& Freeman, J. (2003). Comparison of the effect of detergent versus hypochlorite cleaning on environmental contamination and incidence of Clostridium difficile infection. J Hosp Infect 54, 109-114. 